\title{
Methylphenidate Response, Psychopathology and Tardive Dyskinesia as Predictors of Relapse in Schizophrenia
}

\author{
leffrey A. Lieberman, M.D., Jose Alvir, Dr. P.H., Stephen Geisler, M.D., \\ Jorge Ramos-Lorenzi, M.D., Margaret Woerner, Ph.D., Hana Novacenko, M.A., \\ Thomas Cooper, M.A., and John M. Kane, M.D.
}

Despite the proven efficacy of acute and maintenance pharmacotherapy in schizophrenia, practical methods for identifying patients who require continuous treatment to prevent relapse have not been established. We hypothesized that a pathologic overactivity of mesolimbic and mesocortical dopamine neural systems, that mediates positive psychotic symptoms in the acute phase of the illness, persists in some outpatients who are vulnerable to relapse despite appearing clinically stable. To test and determine if putative measures of central nervous system dopamine activity predict outcome, 41 stable outpatients receiving neuroleptic maintenance treatment underwent provocative tests with methylphenidate in a randomized double-blind placebo controlled design in which behavioral, neuromotor, biochemical, and cardiovascular responses were measured. Patients were then withdrawn from medication and monitored for 52 weeks, or until relapse. The results indicate that psychotic symptoms and their activation by methylphenidate, and the presence of tardive dyskinesia are associated with each other and with a higher risk of relapse. These findings partially support our hypothesis and offer potentially useful measures for the identification of candidates for reduced dose neuroleptic maintenance treatment strategies in schizophrenia. [Neuropsychopharmacology 11:107118, 1994]
KEY WORDS: Schizophrenia, relapse; Dopamine; Methylphenidate

Despite the proven efficacy of neuroleptic drugs in preventing psychotic relapse, much remains to be done to maximize their benefit to risk ratio in the context of maintenance treatment strategies (Gardos et al. 1978; Schooler 1991). Numerous placebo (PBO) controlled maintenance treatment studies have shown an average of a $40 \%$ difference in relapse rates favoring neuroleptic treatment (Davis 1975; Kane et al. 1987). How-

From the Hillside Hospital, Long Island Jewish Medical Center, Albert Einstein College of Medicine (JAL, JA, SG, JR-L, MW, JMK); New York State Psychiatric Institute, Columbia College of Physicians and Surgeons (HN, TC), and Nathan Kline Research Facility (TC).

Address correspondence to: Jeffrey A. Lieberman, M.D., Hillside Hospital, P.O. Box 38, Glen Oaks, NY 11004.

Received January 10, 1994; revised March 30, 1994; accepted April 18, 1994. ever, it is apparent that significant numbers of patients still relapse while taking medication, whereas others taking PBO do not. In addition, studies have demonstrated that many patients can be successfully treated with "low doses" of neuroleptics (less than $25 \%$ of the standard dose range) (Kane et al. 1983; Marder et al. 1987; Hogarty et al. 1988) whereas targeted/intermittent neuroleptic treatment strategies (Pietzcker et al. 1986; Jolley et al. 1989; Carpenter et al. 1990; Herz et al. 1991) may be employed in patients who refuse continuous maintenance treatment. These studies have demonstrated that the increased risk of relapse associated with low dose and targeted treatment may be offset by fewer behaviorally manifest extrapyramidal side effects (e.g., akinesia, akathisia) and improved social functioning (Kane et al. 1985; Marder et al. 1987; Carpenter et al. 1990; Herz et al. 1991). In addition, studies of tardive dyskinesia (TD) have shown that there 
is a TD incidence of approximately $5 \%$ per year of neuroleptic exposure (Kane et al. 1985a). Preliminary evidence from treatment studies indicates that patients receiving reduced dose treatment had lower ratings of abnormal movements compared to patients who received continuous standard dose medication (Kane et al. 1985b).

The therapeutic and prophylactic value of neuroleptic drugs is evident when examining groups of patients, but there are no proven clinical measures that identify the individual patients at greatest risk of relapse, or that measure those who are candidates for drug withdrawal, or reduced dose maintenance treatment strategies. Consequently, standard clinical practice has been to maintain patients on standard doses of neuroleptic drugs indefinitely. This practice is not optimal for all patients.

Previous studies have suggested the utility of various measures as predictors of relapse (Lieberman and Kane 1986c). The most promising of these are measures of central nervous system (CNS) dopamine (DA) activity including plasma prolactin levels (PRL) (Brown et al. 1981; Zander et al. 1981; Wistedt et al. 1982; Lieberman et al. 1986a), growth hormone response to DA agonist stimulation (Cleghorn et al. 1983; MuellerSpahn et al. 1984; Lieberman et al. 1986), plasma neuroleptic levels (Brown et al. 1982; Brown et al. 1985; Marder et al. 1987), pHVA (Davidson et al. 1991) and behavioral response to DA agonist stimulation (van Kammen et al. 1982; Davidson et al. 1987; Lieberman et al. 1987b; Angrist et al. 1981). The latter line of investigation is based on the finding originally demonstrated by Janowsky et al. (1973) and Angrist et al. (1980) that a single or brief administration of a DA agonist can induce psychotic symptoms in schizophrenics in doses that would not induce psychosis in normalsubjects (Lieberman et al. 1987a). This increased vulnerability to the psychotogenic effects of indirect DA agonists in patients with schizophrenia is believed to be a state dependent phenomenon produced by increased DA neuronal activity (Janowsky et al. 1973; van Kammen et al. 1982). We hypothesized that this reflects the pathologic overactivity of mesolimbic and mesocortical DA neural systems that characterizes the acute phase of the illness and can persist in some stable outpatients whose behavioral symptoms have remitted (Lieberman et al. 1987b). Such patients, although appearing to be clinically stable, are hypothesized to be physiologically unstable and prone to symptom exacerbation if pharmacologically perturbed by DA agonist administration, or the discontinuation, or reduction of dopamine antagonism. Thus, behavioral response to a provocative test with a DA agonist could be an indicator of instability and of increased risk of relapse, particularly under conditions of neuroleptic dose reduction or discontinuation.

This study was designed to test if behavioral response to methylphenidate (METHYL), an indirect act- ing DA agonist, predicts outcome, and to assess the relationship of other indices of CNS DA activity to behavioral response and outcome in stable outpatients who are candidates for withdrawal from neuroleptic maintenance treatment. Methylphenidate is a nonamphetaminelike psychostimulant that binds to the DA transporter and inhibits the reuptake of DA by presynaptic neurons (McMillen 1983). It has been found to have more potent psychotogenic effects than amphetamine-like stimulant drugs (Janowsky et al. 1976; Lieberman etal. 1987a). Our primary hypothesis was that patients who have psychotic symptom activation with methylphenidate would relapse more rapidly and in greater proportion than patients who did not. In addition, we hypothesized that other measures that were regulated, at least in part, by DA systems (growth hormone [GH], PRL, pHVA, blink rate, and TD) would exhibit enhanced re sponses to methylphenidate in patients with psychotic symptom activation compared to patients who don't. We have previously published the preliminary results of selected variables from the study (Lieberman et al. 1984; Lieberman et al. 1987b) and now report the full results of the completed study.

\section{SAMPLE AND METHODS}

\section{Sample}

All patients in the Aftercare Service of the Hillside Hospital, division of Long Island Jewish Medical Center, Glen Oaks, NY were screened for study eligibility. The study protocol had been reviewed and approved by the Institutional Review Board of the Medical Center. Eligible patients met the following criteria:

1. They had a diagnosis of subacute, subchronic, chronic schizophrenia, or schizoaffective disorder according to the Research Diagnostic Criteria (Spitzer et al. 1977).

2. Their ages ranged from 18 to 50 years.

3 . They had no history of serious neurologic or endocrine disorders and no current serious medical conditions.

4. They were in a state of relative remission as defined by the following ratings on items from the Sched or Affective Disorders and Schizophrenia-Psychosis and Disorganization (SADS-PD) items: (a) a rating no greater than 2 for severity of delusions (only suspected of being present by the rater); (b) a rating no greater than 2 for severity of hallucinations (only suspected of being present by the rater); (c) a rating no greater than 3 for incoherence ( $a$ few definite instances of impairment in understandability, but they are never gross); (d) a rating no greater than 3 for bizarre behavior (strange behavior, but not obviously crazy); and (e) catatonic motor behavior not present. In addition, a sum 


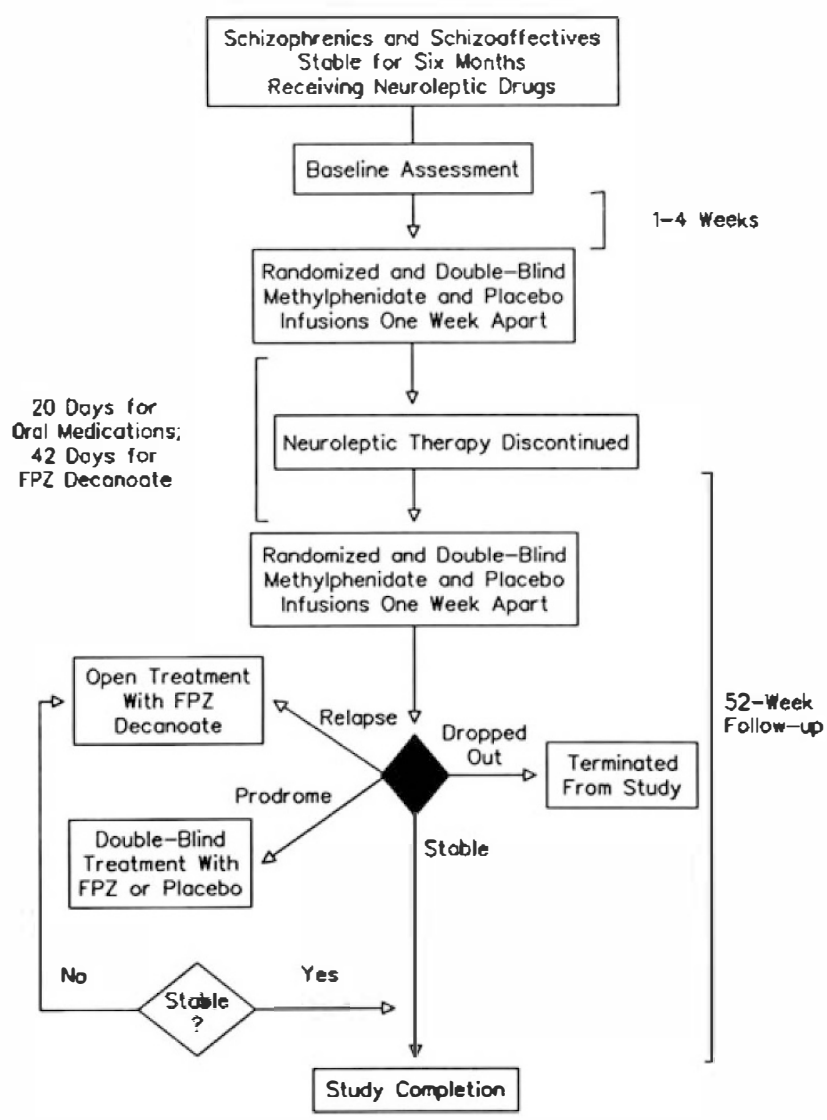

Figure 1. Overall study design. FPZ indicates fluphenazine.

of scores on factors III (conceptual disorganization, grandiosity, hallucinatory behavior, unusual thought content), IV (tension, mannerisms and posturing, excitement), and V (hostility, suspiciousness, uncooperativeness) of the brief Psychiatric Rating Scale (BPRS) was lower than 24.

5. They were stable at the above level of remission for at least six months while receiving medication and wanted to discontinue neuroleptic maintenance treatment.

6. They were willing and able to give informed consent.

Forty-eight patients who met the inclusion criteria provided informed consent and entered the study. Seven of these patients were excluded from the data analyses for the following reasons: two had been withdrawn from the study because new information led to revision of their diagnoses (revised diagnoses were confirmed by nonstudy personnel blind to the patients' study outcomes); one patient relapsed prior to the first infusion procedure; and four dropped out while going through the infusion phase. The sample employed for analyses included 25 males and 16 females with a mean age of $28.9 \pm 6.2$ years. Sixty-seven percent of the patients were white and $33 \%$ were black. Seventy-three percent of patients were diagnosed with schizophre- nia and $27 \%$ with schizoaffective disorder, mainly schizophrenic by Research Diagnostic Criteria (Spitzer et al. 1977). Patients had a mean age at onset of $22.6 \pm$ 4.5 years and $2.7 \pm 2.1$ prior hospitalizations. All were stable outpatients living in the community with a mean \pm SD duration of remission of $96 \pm 48$ weeks and low levels of residual symptomatology. Mean \pm SD rating scale item scores were at baseline for the BPRS $1.3 \pm$ 0.3 , the SADS-PD $1.3 \pm 0.7$ and the Clinical Global Impression (CGI) severity item $1.9 \pm 0.7$. At study entry $51 \%$ of patients were receiving oral neuroleptics and $49 \%$ were receiving long-acting injectable neuroleptic treatment. The mean (SD) dose in chlorpromazine equivalents was $426 \pm 712 \mathrm{mg} / \mathrm{d}$. Fifty-four percent of the patients had TD defined as a global rating of "mild" or greater on the SDS. The high rate of TD was because stable patients with neuroleptic induced side effects are candidates for drug withdrawal and therefore were selectively referred for the study. In addition, because diagnoses of TD were based on examinations of patients while taking and not taking medications, any covert dyskinesias were likely to be unmasked.

\section{Procedures}

The study design is illustrated in Figure 1.

\section{Infusions}

Patients underwent two infusions, one of METHYL and one of $\mathrm{PBO}$, in randomized order under double blind conditions, one week apart. Prior to the first procedure, patients underwent a physical exam and an EKG. During the infusion procedures, the cardiac rhythms of patients were continuously monitored. Six patients who entered the study during an earlier protocol design received only one set of infusions (METHYL and PBO), 20 days after neuroleptic discontinuation. Twenty-seven patients had the complete set of four infusions (two while receiving neuroleptic maintenance treatment and two after withdrawal from it). The withdrawal period prior to the second set of infusions was 20 days for patients on oral medication and 42 days from long-acting injectable medication. Eight patients had the infusions while on medication because they relapsed during the withdrawal period prior to the second set of infusions.

A standardized protocol was used for all infusions. The procedure was conducted between 8:30 A.M. and 12:00 P.M. in the biologic studies laboratory. After an all-night fast (and at 12 hours after taking their last dose of medication during on-medication procedures), the patient underwent a brief standardized examination for TD that was scored on the Hillside modified version of the Simpson Dyskinesia Scale (Lieberman et al. 1984), and then was placed in a comfortable supine position on a hospital bed. An indwelling catheter (19-gauge 
scalp vein) was inserted into a forearm vein, secured, and connected to a slow-running infusion system kept patent with heparinized saline solution. After an adaptation period of 45 minutes, blood samples were collected through the catheter at 20-minute intervals for 60 minutes. Blood pressure, pulse rate, and blink rate were also measured. During this period, a preinfusion evaluation was completed by a research psychiatrist and scored on the SADS-PD, the BPRS, and the CGI rating scales.

After the preinfusion period, $0.5 \mathrm{mg} / \mathrm{kg}$ of METHML, or an equivalent volume of saline solution was administered intravenously in the contralateral arm over a period of 120 seconds. The patient was interviewed informally and observed continuously for 80 minutes following the infusion. The patient's highest level of behavioral symptomatology was rated on every behavioral item of the SADS-PD and BPRS for the total postinfusion period. Postinfusion blood pressure and pulse rate were monitored at ten-minute intervals; blood samples were collected at 20-minute intervals; blink rate was measured at 30-minute intervals. On completion of the postinfusion period, the catheter was withdrawn and the TD examination was repeated. At the end of the procedure, patients were given an intramuscular dose equivalent to $250 \mathrm{mg}$ of chlorpromazine of whichever neuroleptic drug they had most recently been treated with, along with $2 \mathrm{mg}$ of benztropine by mouth to counteract any activated symptoms.

\section{Biochemical Measures}

Five cc samples of whole blood were collected in heparinized tubes at room temperature at $-45,-25$, and -5 minutes preinfusion and 20, 40,60 minutes postinfusion for determination of PRL and GH. All specimens were centrifuged at 5,000 RPMs. The plasma was separated into polypropylene tubes and immediately frozen at $-20^{\circ} \mathrm{C}$ until analysis. Eight cc samples of whole blood were collected in glass tubes containing EDTA and sodium metabisulfate at -5 minutes preinfusion and 40 and 60 minutes post infusion for HVA determination. All specimens were centrifuged at 5,000 RPMs for 15 minutes, and then the plasma was pipetted into glass tubes and immediately frozen at $-20^{\circ} \mathrm{C}$ until analysis.

Plasma PRL was measured by a double antibody radioimmunoassay (Sinha et al. 1973). Prolactin standard (hPR1-RP-1) and the primary antiserum were donated by the National Pituitary Agency. The labeled PR1-I 125 was purchased from New England Nuclear and repurified before use on a G-100 Sephadex column. Antirabbit globulin serum was used to separate the bound and free fractions. Samples were assayed in duplicate. The intraassay and interassay coefficients of variation were $6.4 \%$ and $6.9 \%$ at $3.76 \mathrm{ng} / \mathrm{ml} ; 3.8 \%$ and
$5.7 \%$ at $27.0 \mathrm{ng} / \mathrm{ml}$; and $2.0 \%$ and $3.5 \%$ at $46.3 \mathrm{ng} / \mathrm{ml}$. Growth hormone was analyzed by radioimmunoassay (Glick et al. 1963). The coefficients of variation within and between assays were for concentrations of $1.5 \mathrm{ng} / \mathrm{ml}$ at $9.6 \%$ and $12.4 \% ; 7.5 \mathrm{ng} / \mathrm{ml}$ at $3.2 \%$ and at $3.8 \% ; 33$ $\mathrm{ng} / \mathrm{ml}$ of $2.6 \%$ and at $3.9 \%$. For the quantification of plasma HVA, we adapted the method of Fri et al. (1974) using gas chromatography mass spectroscopy (GCMS). Using pentadeuterated HVA as interval standard, 0.5 $\mathrm{ml}$ of plasma was diluted with aqueous buffer $(\mathrm{pH} 4.0)$ and extracted with ethyl acetate. The ethyl acetate was then placed in a tapered tip glass tube containing 50 $\omega$ pentafluoropropionic anhydride (PFPA) and taken to dryness via a vacuum centrifuge at $40^{\circ} \mathrm{C}$. PFPA and trifluoroethanol $(4: 1)$ were added and incubated at $75^{\circ} \mathrm{C}$ for 15 minutes and again taken to dryness. The residue was redissolved in $30 \omega$ cyclohexane. One $\omega$ was then injected into a capillary GCMS using the cold trapping procedure with the mass spectrometer operated in the electron impact mode utilizing simultaneous ion monitoring of the molecular ion $410 \mathrm{~m} / \mathrm{z}$ and the internal standard molecular ion $415 \mathrm{~m} / \mathrm{z}$. Secondary ions at $283 \mathrm{~m} / \mathrm{z}$ and $288 \mathrm{~m} / \mathrm{z}$ were monitored for additional specificity. The method has an intraassay and interassay coefficient variation of $4.2 \%$ and $6.1 \%$. Standard curves are linear through $50 \mathrm{ng} / \mathrm{mL}$ with negligible intercept and a lower limit of sensitivity of $0.5 \mathrm{ng} / \mathrm{mL}$.

\section{Definition of Behavioral Response}

Infusion responses were classified according to the following predetermined criteria: A positive response was defined as an increase of at least two scale points above the threshold of any of the critical SADS-PD items used to define remission, or an eight-point or greater increase from the total preinfusion BPRS scores on eight critical items (conceptual disorganization, bizarre behavior, grandiosity, hostility, suspiciousness, hallucinations, unusual thought content, and uncooperativeness). An increase of one scale point above the SADS-PD item thresholds or a six-point increase in the BPRS critical items score was a questionable response. True-positive responders were those who had positive change scores to METHYL only (and not PBO). Negative responders were those who had negative responses to all infusions.

\section{Follow-Up}

Patients were seen weekly by their treating psychiatrist during the drug washout period between infusions and for ten weeks following the infusions and for ten weeks following the infusions; thereafter, they were seen biweekly. The treating psychiatrists were blind to the patient's infusion response. Assessments at each clinic visit were scored on the BPRS, a prodromal symptom 

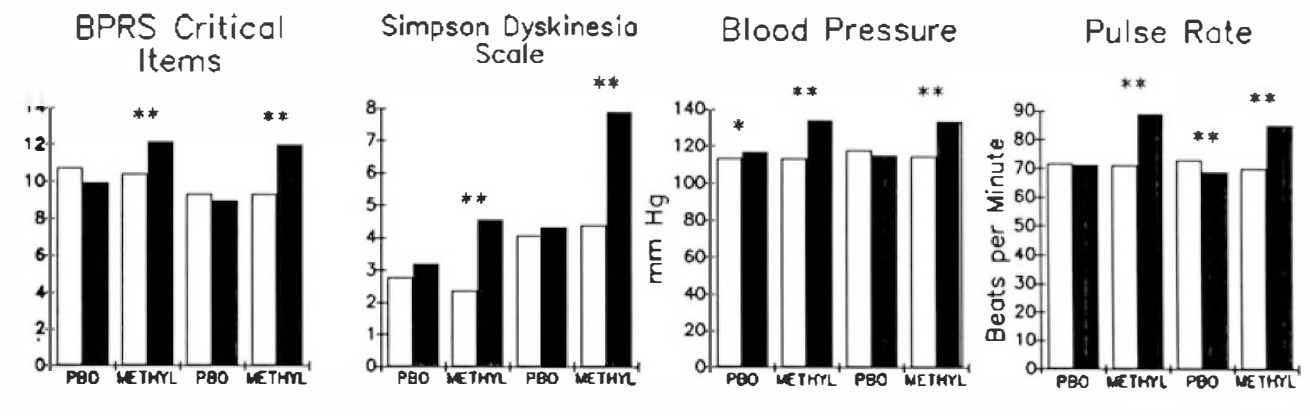

Blink Rate

Growth Hormone

Prolactin

HVA
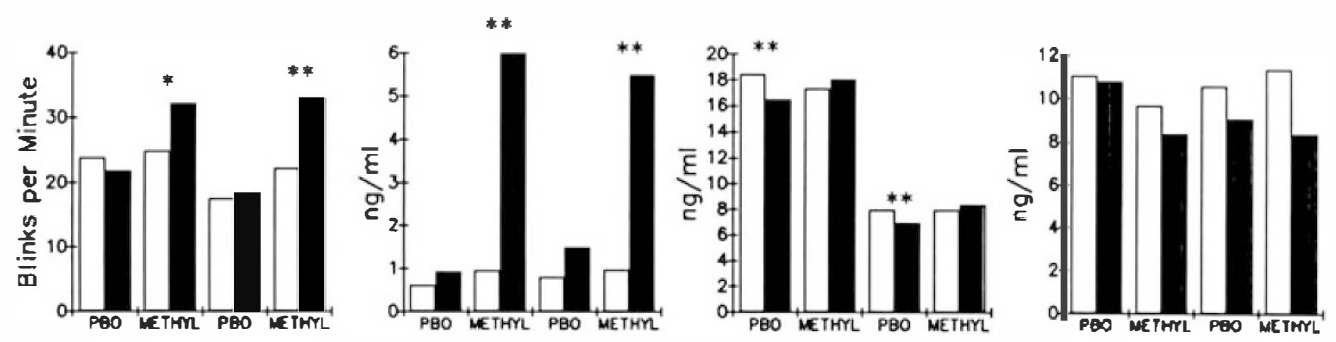

Figure 2. Clear bars represent preinfusion measures while solid bars represent postinfusion measures. The four bars on the left of each graph represent infusions done while on neuroleptics whereas the four bars on the right represent infusions done while off neuroleptics. Pairwise comparisons of the preinfusion and postinfusion ratings were done using paired $t$-test on all subjects who had available pairwise data $\left({ }^{\star} p<.05 ;{ }^{\star \star} p<.01\right)$.

scale adapted from Herz and Melville (1980) and CGI. Prodromal symptoms are nonpsychotic symptoms including anxiety, sleep disturbance, and irritability that have been hypothesized to precede psychotic relapse (Carpenter et al. 1987; Herz and Melville 1980). Patients were maintained entirely drug free for 52 weeks, or until manifestations of psychopathology recurred. To evaluate the predictive validity of prodromal symptoms, criteria were established to define prodromal status. If patients met prodromal status criteria, they were randomly assigned to treatment for eight weeks with 10 $\mathrm{mg} / \mathrm{d}$ of fluphenazine hydrochloride by mouth, or PBO under double-blind conditions. If the patient was stable and no longer exhibited prodromal symptoms by the end of this period, medication was discontinued. If at any time patients exhibited symptoms of relapse, they were treated as clinically indicated. Five of the patients in this study exhibited symptoms meeting the prodromal criteria. Because an unbalanced randomization schedule was employed, only one patient was assigned to active fluphenazine treatment after prodromal symptoms developed; thus, the course of the PBO-treated patients could be monitored. (Results of the prodromal and treatment-outcome portion of the study will be presented in a separate report.)

Relapse was defined as an increase of at least two scale points above the threshold on any of the critical SADS-PD items used to define remission, and/or a tenpoint increase or greater from the baseline scores of the critical BPRS items, and a CGI scale improvement item rating of six (much worse) or greater.

\section{Statistical Methods}

Analyses of preinfusion (basal unstimulated) and postinfusion (stimulated) measures with and without neuroleptic drugs were done using paired $t$ tests. Multivariate repeated-measure analyses of variance were used to assess the effects of neuroleptic exposure and METHYL infusion on preinfusion and postinfusion scores. Chi-square analyses with the Yates correction were performed on categorical variables. Survival analyses were done for the time to relapse across groups defined by behavioral response to methylphenidate and by the presence of TD. Cox proportional hazards regression analysis was used to examine the effects of continuous measures on time to relapse. Survival analysis is particularly appropriate for the data on time to relapse because the exact survival times are unknown for individuals who either did not complete the study, or are still stable at the end of the study period. Survival analysis takes such censored data into account when it estimates survival time (Lee 1980).

\section{RESULTS}

Behavioral and physiologic responses to methylphenidate and placebo are shown in Figure 2. To analyze for drug effects and interactions, repeated measures analysis of variance was performed on the preinfusion and postinfusion measures over the four infusion conditions. The within subject factors included in the analy- 
Table 1. Infusion Response Rates

\begin{tabular}{|c|c|c|c|c|c|}
\hline \multirow[b]{2}{*}{$\begin{array}{l}\text { Methylphenidate } \\
\text { Response }\end{array}$} & \multirow{2}{*}{$\begin{array}{c}\text { All Infusion } \\
\text { Combined } \\
(n=41)\end{array}$} & \multicolumn{2}{|c|}{ Infusions } & \multicolumn{2}{|c|}{$\begin{array}{l}\text { Patients Who Had } \\
\text { Infusions in Both } \\
\text { Conditions }\end{array}$} \\
\hline & & $\begin{array}{l}\text { On Meds } \\
(n=35)\end{array}$ & $\begin{array}{l}\text { Off Meds } \\
(n=33)\end{array}$ & $\begin{array}{l}\text { On Meds } \\
(n=27)\end{array}$ & $\begin{array}{c}\text { Off Meds } \\
(n=27)\end{array}$ \\
\hline$\%$ Negative & 63 & 71 & 70 & 78 & 67 \\
\hline$\%$ Questionable & 20 & 17 & 15 & 15 & 18 \\
\hline$\%$ Positive & 17 & 11 & 15 & 7 & 15 \\
\hline
\end{tabular}

sis were neuroleptic status (on versus off neuroleptic), METHYL (PBO versus METHYL), and infusion status (preinfusion versus postinfusion values), and the interactions involving these factors.

As indicated by significant interactions between METHYL and infusion status, METHYL infusion resulted in greater increases as compared to $\mathrm{PBO}$ in BPRS critical items $(F=16.8, d f=1,23, p<.001)$, abnormal movements on the SDS $(F=27.4, d f=1,14$, $p<.001)$, systolic blood pressure $(F=99.3, d f=1,22$, $p<.001)$, pulse rate $(F=85.0, d f=1,22, p<.001)$, growth hormone $(F=18.3, d f=1,23, p<.001)$ and prolactin $(F=9.0, d f=1,23, p=.006)$. SDS ratings were higher (preinfusion and postinfusion on $\mathrm{PBO}$ and METHYL) when patients were off neuroleptics as compared to when they were on neuroleptics $(F=7.3$, $d f=1,14, p=.017)$. In addition, an interaction between neuroleptic, METHYL, and infusion status was seen when the global SDS rating was examined ( $F=7.0$, $d f=1,14, p=.019)$. Prolactin values were lower when off neuroleptics $(F=12.3, d f=1,23, p=.002)$. Postinfusion plasma HVA levels were nonsignificantly decreased from preinfusion levels. This decline appeared to be greater in response to METHYL and in the off neuroleptic condition.

Cardiovascular responses peaked within 20 minutes of METHYL administration and gradually subsided over the remainder of the procedure and in all cases were within physiologically safe and tolerable ranges (Robinson et al. 1988).

Using the a priori definition previously described to classify behavioral response to the infusions, there were $26(63 \%)$ negative, seven (17\%) positive, and eight (20\%) questionable responders (Table 1). No patient had a positive or questionable response to $\mathrm{PBO}$. Among patients who had infusions both on and off neuroleptics, the rate of positive and questionable response was 33\% in the off neuroleptic condition compared to $22 \%$ on neuroleptics, but this difference was not statistically significant $\left(\chi^{2}=1.3, d f=1, p=.38\right)$. Four patients who had negative responses to the on neuroleptic METHYL infusion converted their response status in the off neurolepticMETHYL infusion-three to a questionable response and one to a positive response. One patient who had a questionable response to the on neuroleptic METHYL infusion converted to a positive response in the off neuroleptic infusion. Seventeen patients had negative responses, two had positive responses, and two had questionable responses to METHYL infusions in both conditions. Because the positive and questionable responders to METHYL were widely separated from the negative responders on the magnitude of their BPRS critical item changes, they were combined for the outcome analyses. Hereafter, this combined group is referred to as positive responders.

Positive (plus questionable) and negative responders showed few differences on demographic and clinical variables. There were more female positive responders (56\% as compared to $24 \%$ among males) $\left(\chi^{2}=3.1, d f=1, p=.079\right)$. Positive responders were slightly more symptomatic at baseline scoring $1.4(.30)$ on the overall BPRS score as compared to $1.2(.19)$ among negative responders ( $t_{\text {unequal variances }}=2.1, d f=$ $19, p=.055)$. Positive responders also had nonsignificantly higher mean (SD) baseline neuroleptic doses than negative responders (531 [914] versus 356 $[175] \mathrm{mg} / \mathrm{d}$; $t_{\text {unequal variances }}=0.73, d f=15, p=.47$ ). There was no difference in the number of patients who entered the study on fluphenazine decanoate in the positive and negative responding groups. Positive responders were younger than negative responders at their first psychotic treatment (18.4 [6.1] versus 22.7 [5.5] $\mathrm{yrs} ; t=2.3, d f=37, p=.027)$. Eighty percent of the positive responders had TD compared to $38 \%$ of the negative responders $\left(\chi^{2}=5.0, d f=1, p=.025\right)$. Positive and negative responders did not exhibit significant differences in the biochemical or cardiovascular basal preinfusion measures. However, basal pHVA was higher prior to the off neurolepticinfusions in patients who activated with METHYL compared to nonactivators $(20.4 \mathrm{ng} / \mathrm{ml}$ [15.9] versus $8.4 \mathrm{ng} / \mathrm{ml}$ [4.3] respectively), but was similar prior to the on neuroleptic infusions ( $9.4 \mathrm{ng} / \mathrm{ml}$ [5.2] versus $9.7 \mathrm{ng} / \mathrm{ml} \mathrm{[4.0]} \mathrm{respectively)}$ resulting in a significant METHYL response by neuroleptic status interaction $(F=7.1, d f=1,7, p=.032)$.

Of the 26 negative responders, six did not complete the study during the medication free follow-up phase prior to completing 52 weeks (at weeks 1, 4, 8, 16, 43, 


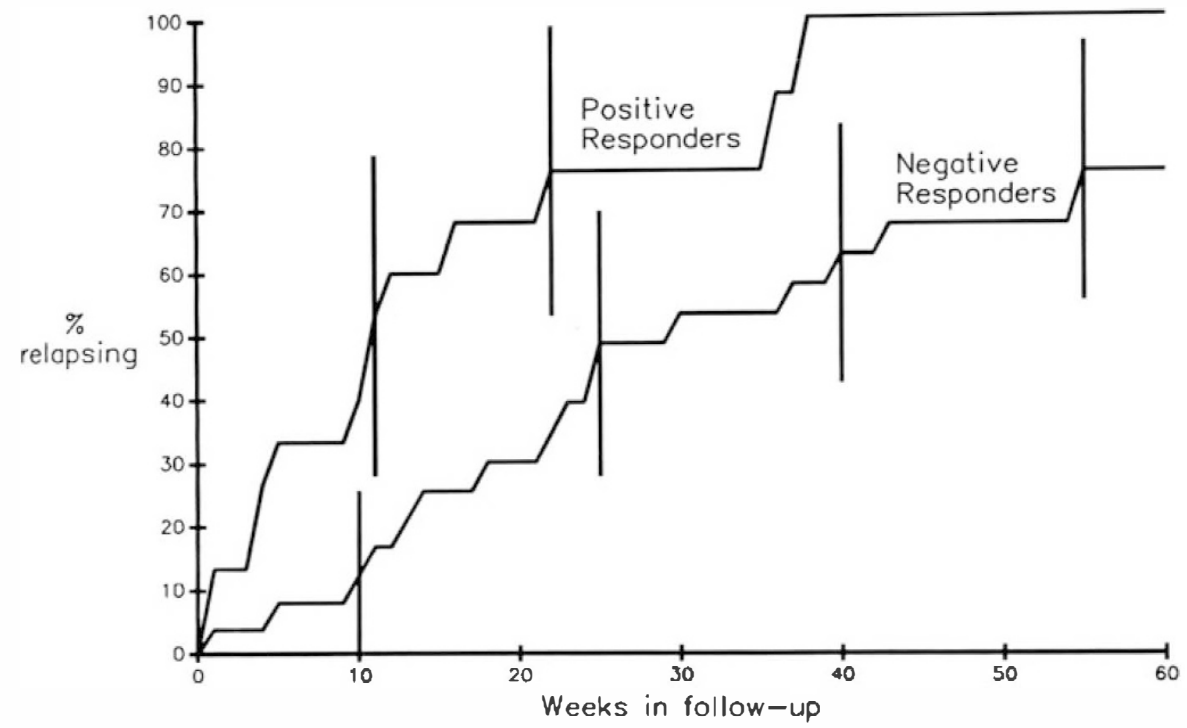

Figure 3. Patients were classified into symptom activators (positive and questionable responders) and nonactivators (negative responders) using a priori criteria. The time to relapse following medication discontinuation is shown. Eightyseven percent of activators relapsed in a mean/median of 15.9/11 weeks; $62 \%$ of nonactivators relapsed in a mean/median of $33.5 / 30$ weeks. Thus, symptom activators relapsed in greater proportion, and more rapidly (Mantel-Cox $=8.5, d f=1$, $p=.004)$ than the nonactivator group. and 46). Five negative responders were stable without relapse through 52 weeks off medication. None of the positive responders remained relapse free through 52 weeks. Two positive responders were considered dropouts from the study (at weeks 13 and 34). One of these developed prodromal symptoms in the course of follow-up and was assigned to active treatment (under double-blind conditions) according to the protocol and, therefore, could not be followed to relapse. The other who developed prodromal symptoms refused medication and was lost to follow-up. Positive responders thus relapsed more often $\left(\chi^{2}=4.9, d f=1, p=.027\right)$ and more rapidly than negative responders. The mean \pm SE relapse for the negative responders was $33.5 \pm$ 4.3 weeks compared to $15.9 \pm 3.6$ weeks for the positive responders. Median $\pm \mathrm{SE}$ time to relapse was also dramatically different between groups, $30 \pm 8$ weeks for negative responders and, $11 \pm 1.3$ weeks for positive responders (Figure 3 ). Survival analysis comparing time to relapse as a function of behavioral response to METHML revealed a significant relationship between positive response and shorter survival (Mantel-Cox = 8.5, $d f=1, p=.004$ ).

Additional survival analyses were completed employing baseline demographic (age, gender, and socioeconomic status) and clinical (age of onset, diagnosis, number of prior episodes,duration of stability, neuroleptic dose, symptomatology, and TD status) variables as predictors of time to relapse. Baseline symptomatology and TD status emerged as significant predictors. Patients with higher baseline scores on the BPRS critical items used to define stability and infusion response (conceptual disorganization, bizarre behavior, grandiosity, hostility, suspiciousness, hallucinations,

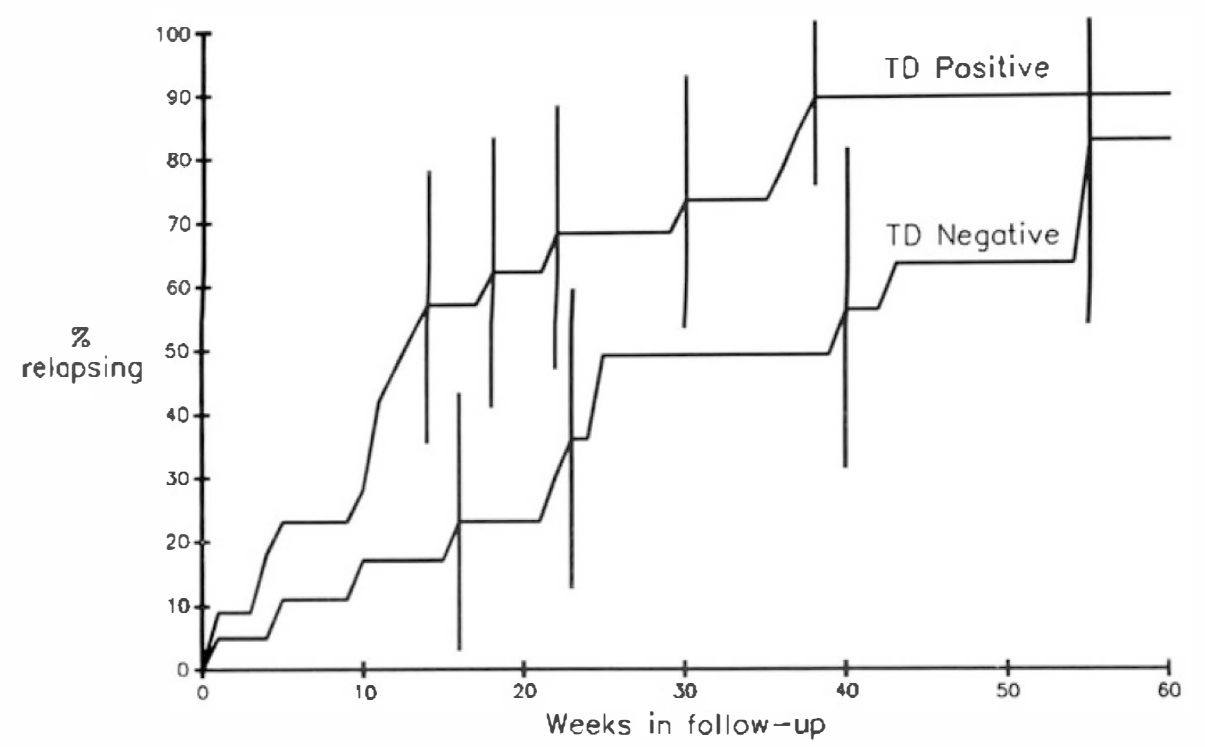

Figure 4. Patients were classif ied as TD positive or TD negative based on their SDS global rating from TD exams in the on and off neuroleptic infusion procedures. The time to relapse following medication discontinuation is shown. Eighty-two percent of TD positive patients relapsed in a mean/median of $21 / 13$ weeks whereas $58 \%$ of TD negative patients relapsed in 34/40 weeks (Mantel-Cox $=4.1, d f=1, p=$ $.043)$. 
Figure 5. The effects of behavioral response to METHYL and TD on time to relapse as predicted from the Cox regression model are shown. METHYL = yes $(Y)$ refers to symptom activators), METHYL = no $(\mathrm{N})$ (refers to nonactivators); $\mathrm{TD}=$ yes (refers to patients with $\mathrm{TD}$ ), and TD = no (refers to patients without TD). The top curve (METHYL $=$ Y; TD $=$ Y) represents 12 patients who were symptom activators to METHYL and also had diagnoses of TD $(n=12)$. This group had the poorest outcome in terms of likelihood and time to relapse. The second curve from the top (METHYL $=\mathrm{Y}$; TD $=n$ ) represents three patients who were symptom activators, but did not have TD. The third curve from the top $(\mathrm{METHYL}=n$; TD $=\mathrm{Y}$ ) represents 10 patients who were nonactivators to METHYL, but had TD $(n=10)$. The bottom curve $(\mathrm{METHYL}=\mathrm{N}$; TD $=\mathrm{N})$ represents 16 patients who were nonactivators to METHYL and did not have TD. Regression analyses indicated combined effect of METHYL and TD on survival $(p=.008)$ and an individual effect of METHYL when TD was controlled for $(p=$ .028). TD did not significantly predict survival when the effects of METHYL were controlled for $(p=.22)$.

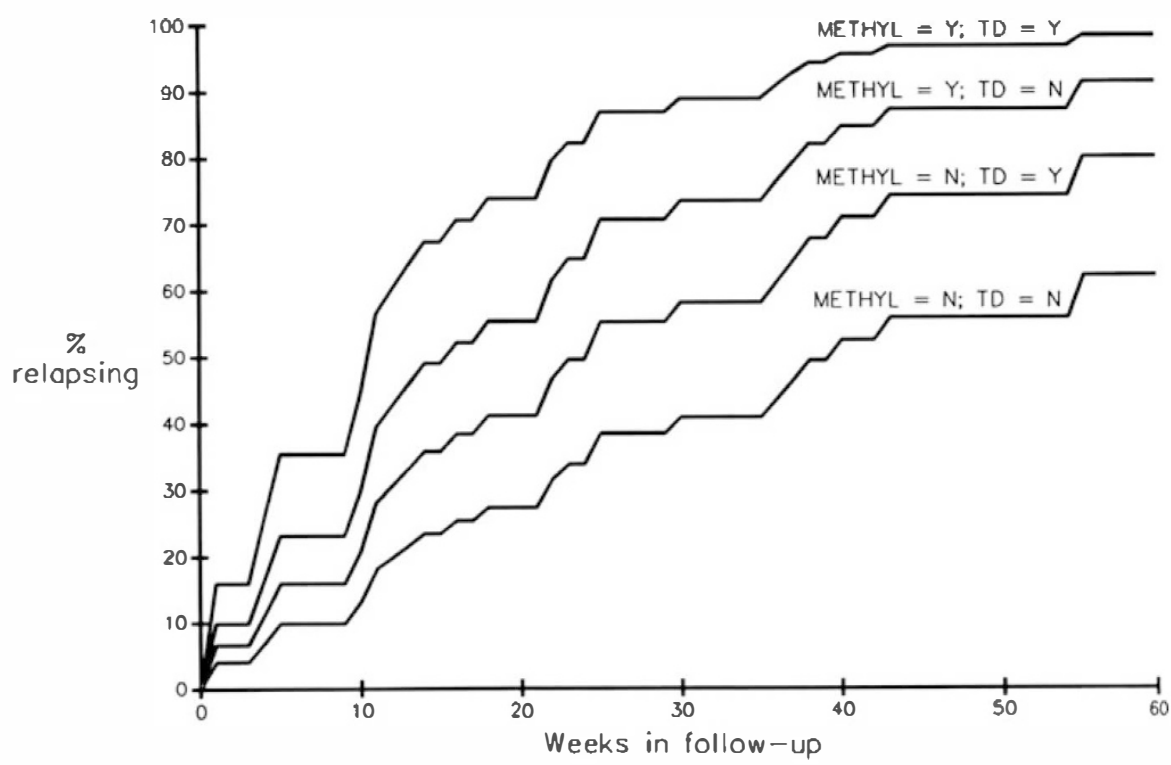

unusual thought content, uncooperativeness) had shorter time to relapse $\left(\chi^{2}=5.35, d f=1, p=.02\right)$. Patients with TD had a mean $\pm \mathrm{SE} /$ median $\pm \mathrm{SE}$ time to relapse of $20.8 \pm 4.0 / 13 \pm 2.3$ weeks compared to $34.2 \pm 4.9 / 40 \pm 10.7$ weeks for patients without TD (Mantel-Cox $=4.1, d f=1, p=.043$ ) (Figure 4).

Because METHYL response, symptomatology, and TD were associated with outcome, survival analysis using the Cox proportional hazards model was performed to examine the combined and independent effects of these variables on time to relapse. The combined effects of METHYL response, symptomatology, and TD status on time to relapse were highly significant (Global $\chi^{2}=16.8, d f=2, p=.0008$ ). When the effects of the three variables were examined individually while controlling for the effects of the others, only symptomatology $\left(\chi^{2}=4.5, d f=1, p=.035\right)$ and METHYL response $\left(\chi^{2}=2.7, d f=1, p=.098\right)$ remained associated with time to relapse. Using the Cox proportional hazards model to predict relapse for the four possible combinations of METHYL response and TD indicated a hi- erarchical relationship, whereas patients with positive METHYL response and TD had the shortest survival time, followed by positive METHYL responders without TD, and negative METHYL responders with TD; negative METHYL responders without TD had the best outcomes (Figure 5).

Of the biochemical variables (PRL, GH, HVA), only basal PRL levels were associated with outcome. Using Cox proportional hazards regression analyses, the preinfusion basal PRL levels in the on-neuroleptic conditions and off-neuroleptic conditions were associated with risk of relapse. On-neuroleptics, patients with higher basal PRL levels had a greater risk of relapse $\left(\chi^{2}=7.2, d f=1, p=.009\right)$; off-neuroleptics, patients with lower basal PRL levels had a greater risk of relapse $\left(\chi^{2}=4.5, d f=1, p=.035\right)$. The difference between the on-neuroleptic preinfusion PRL levels and the offneuroleptic preinfusion PRL levels of patients was also examined. Greater decreases in PRL from the onneuroleptic conditions to the off-neuroleptic conditions were associated with greater risk of relapse $\left(\chi^{2}=8.6\right.$, 
$d f=1, p=.003)$. The pattern of results was not altered by the log transformation of the data done to normalize the distribution of PRL values.

\section{DISCUSSION}

These results demonstrating the relationship between behavioral response to METHYL and to outcome in terms of the likelihood of and time to relapse extremes confirms our previous findings and is consistent with other reports of an association between behavioral perturbation with indirect acting DA agonists and an increased risk of relapse in stable patients with schizophrenia (Angrist et al. 1981; van Kammen et al. 1982; Davidson et al. 1987; Lieberman et al. 1987b). These findings are consistent with the hypothesis that some clinically stable patients may be physiologically unstable and will relapse if they are withdrawn from neuroleptic treatment (or if their maintenance dose is significantly lowered); these patients are susceptible to psychotic symptom provocation by METHYL or other behaviorally active DA agonists. Alternatively, the periodicity of schizophrenia may be such that the underlying pathophysiological process precedes and extends beyond the period of acute symptomatology. Consequently, patients who are verging on relapse or who have recently recovered from an episode may be susceptible to pharmacologic perturbation despite their asymptomatic appearance. The latter interpretation is consistent with the hypothesis that susceptibility to the psychotogenic effects of psychostimulants is a state dependent phenomenon as demonstrated previously by Janowsky et al. (1973) and van Kammen et al. (1982) and reported by our laboratory (Lieberman et al. 1989; 1993; Jody et al. 1990); however, it is also possible that some patients are persistently susceptible to pharmacologic perturbation. Duration of stability prior to study entry was not correlated with METHYL response or outcome supports this idea; thus, we believe that a subgroup of patients is persistently sensitive to DA agonist stimulation, whereas other patients are susceptible only during (or in close temporal proximity to) exacerbation of their illness.

Positive METHYL responders had higher baseline symptom ratings which suggests that these patients may have been more severely ill; however, it should be emphasized that none of the patients were clinically unstable or outside the range of symptomatology normally characteristic of the stable ambulatory schizophrenic population of our institution. Moreover, despite the statistical significance of the relationship between baseline symptomatology and outcome, it must be emphasized that the differences in baseline symptoms among patients who subsequently relapsed quickly were not clinically obvious, or such that patients could have been identified. In this sense, the METHYL procedure served to provoke or amplify clinical features of the disease that were not perceptibly apparent in patients under basal conditions.

The other clinical variable that was related to behavioral response to METHYL and outcome was TD. The fact that patients with TD relapsed faster and in greater proportion than patients without TD raised the possibility of an interaction between treatment and course of illness. However, patients with and without TD did not differ on illness course characteristics (duration of illness, number of prior episodes, medication dose). Because patients with TD were significantly more likely to be positive METHYL responders, suggests that both variables reflect a common pathological process. In clinical terms there are two interpretations of these findings. A subgroup of patients may be predisposed to the development of TD as well as to be highly sensitive to the psychotogenic effects of METHYL. Alternatively, patients who develop TD may be, as a consequence, more sensitive to the behavioral effects of METHYL. Behavioral analogues of TD have been postulated (Davis et al. 1979; Chouinard et al. 1980), but never proven (Weinberger et al. 1981; Hunt et al. 1988). It cannot be determined if the outcome of patients in this study was due to idiopathic, or treatment effects, or their interaction; however, it is apparent that outcome in terms of the likelihood and rapidity of relapse could be influenced by DA neural activity that may be reflected by METHYL response and TD. It is our hypothesis that the functional state of the hyperactive mesocortical and mesolimbic DA neurons that are believed to mediate the positive psychotic symptoms of schizophrenia also determine the susceptibility to psychotogenic response to METHYL and relapse and that this is a genetically determined trait (Piazza et al. 1989). These neural systems have previously been shown to be sensitive to stress and pharmacologic stimulation that enhances DA neurotransmission (Kalivas et al. 1988); Lee et al. 1988; Roth et al. 1988). Csernansky et al. (1991) has proposed a model in which ventrotegmental DA neurons modulate the function of a limbic circuit involving the ventromedial caudate, nucleus accumbens, amygdala, hippocampus, and cingulate cortex. In this model, environmental or pharmacologic perturbations that acutely increases DA neurotransmission produce disinhibition of the limbic circuit that in turn leads to expression of psychosis. We further speculate that patients with this physiologic trait have an increased susceptibility to develop TD with sufficient neuroleptic exposure. Previously reported data (Csernansky et al. 1986; Newcomer et al. 1992) are consistent with this hypothesis. They found that positive symptom ratings were higher in patients with TD and correlated inversely with plasma PRL. Moreover, in the current study, lower basal PRL of neuroleptics and a greater decline in PRL 
with neuroleptic withdrawal was associated with greater relapse risk. This may reflect emergent DA activity in the tuberoinfundibular system following neuroleptic withdrawal (and exerts inhibitory effects on PRL) and parallels similarly increased DA activity in the mesolimbic and mesocortical systems. The association between higher basal PRL on neuroleptics and a greater risk of relapse might be the result of a neuroleptic effect. More severely ill patients may receive higher neuroleptic doses that produce greater PRL elevation. In this way, neuroleptic dose may more accurately represent the patient's true illness severity than symptoms that are suppressed by treatment. Such patients might be expected to have a higher risk of relapse; however, neuroleptic dose itself was not associated with relapse risk. Thus, the on-medication PRL association with outcome may reflect a more complex interaction of drug-patient factors in terms of pharmacologic responsivity in the pituitary rather than drug dose alone (Lieberman et al. 1986a).

Also, partially consistent with our hypothesis was the observation that basal pHVA in the off-neuroleptic condition was higher in patients who activated with METHYL. This, as did the PRL data, suggests that DA neurons may have been unsuppressed following neuroleptic withdrawal. The relationship between pHVA and outcome may have failed to reach significance because of the limited sample size on whom pHVA samples were available.

In conclusion, behavioral response to METHYL, and to a lesser extent, TD development with sustained neuroleptic exposure provide a bioassay of CNS DA dysfunction in schizophrenia.

When this study was conducted, the question of whether stable patients with chronic schizophrenia, particularly those with side effects including TD, could be safely withdrawn from neuroleptic maintenance treatment had not yet been answered. The targeted intermittent maintenance treatment strategy was believed to be viable for the long term management of patients. Because of recent studies (Jolley et al. 1989; Carpenter et al. 1990; Herz et al. 1991; Schooler et al. 1993), it is now clear that continuous antipsychotic drug maintenance is the preferred mode of treatment for multiepisode, chronic, schizophrenic patients. Because medication discontinuation is rarely indicated in the long term management of schizophrenic patients, the main practical implementation of provocative tests with psychostimulant drugs will be in identifying candidates for dose reduction, or for patients who insist on discontinuing medication. In such cases, the test results could be a useful deterrent to patients.

\section{ACKNOWLEDGMENTS}

This study was supported by U.S. Public Health Service grant (MH38880) and a Research Scientist Development Award
(MH00537) to Dr. Lieberman and the Mental Health Clinical Research Center for the Study of Schizophrenia (MH41960).

The authors thank Ms. Judy Dunlop, R.N. and Rosalind Felber for their assistance in performance of study procedures and in data collection.

\section{REFERENCES}

Angrist B, Peselow E, Rotrosen J, Gershon S (1981): Relationship between responses to dopamine agonists, psychopathology, neuroleptic main tenance in schizophrenic subjects. In Angrist B, Burrows G, Lader M, et al. (eds), Recent Advances in Neuropsychopharmacology, vol.31, New York, Pergamon Press, pp 49-54

Angrist B, Rotrosen J, Gershon S (1980): Responses to apomorphine, amphetamine, and neuroleptics in schizophrenia subjects. Psychopharmacol 67:31-38

Brown W, Laughren T (1981): Low serum prolactin and early relapse following neuroleptic withdrawal. Am J Psychiatry 138:237-239

Brown WA, Laughren T, Chisholm E, Williams BW (1982): Low serum neuroleptic levels predict relapse in schizophrenic patients. Arch Gen Psychiatry 39:998-1000

Brown WA, Silver MA (1985): Serum neuroleptic levels and clinical outcome in schizophrenic patients treated with fluphenazine decanoate. J Clin Psychopharmacol 5:143147

Carpenter WT, Hanlon TE, Heinrichs DW, Summerfelt AT, Kirkpatrick B, Levine J, Buchanan RW (1990): Continuous versus targeted medication in schizophrenic outpatien ts: Outcome results. Am J Psychiatry 147:1138-1148

CarpenterWT, Heinrichs DW, Hanlon TE (1987): A comparative trial of pharmacologic strategies in schizophrenia. Am J Psychiatry 144:1466-1470

Chouinard G, Jones BD (1980): Neuroleptic-induced supersensitivity psychosis: Clinical and pharmacologic characteristics. Am J Psychiatry 137:16-21

Cleghorn JM, Brown GM, Brown PJ, Kaplan RD, Dermer SW, Crimmon DF, Mitton J (1983): Growth hormone responses to apomorphine HCL in schizophrenic patients on drug holidays and at relapse. Br J Psychiatry 142: 482-488

Csernansky JG, Murphy GM, Faustman WO (1991): Lim$\mathrm{bic} / \mathrm{mes}$ limbic connections and the pathogenesis of schizophrenia. Biol Psychiatry 30:383-400

Csernansky JG, Vinogradov S, Prosser E, Kaplan J, Berger PA, Hollister LE (1986): Associations among plasma prolactin levels, tardive dyskinesia, and paranoia in treated schizophrenics: Relevance to supersensitivity psychosis. Psychopharm Bull 22(3):897-899

Davidson M, Kahn RS, Powchik P, Warne P, Losonczy MF, Kaminsky R, Apter S, Jaff S, Davis KL (1991): Changes in plasma homovanillic acid concentrations in schizophrenic patients following neuroleptic discontinuation. Arch Gen Psychiatry 48(1):73-76

Davidson M, Keefe RSE, Mohs RC, Siever LJ, Losonczy MF, Horvath TB, Davis KL (1987): L-dopa challenge and relapse in schizophrenia. Am J Psychiatry 144:934-938

Davis J (1975): Overview: maintenance therapy in psychiatry: 1. Schizophrenia. Am J Psychiatry 132:1237-1245 
Davis K, Rosenberg G (1979): Is there a limbic system equivalent to tardive dyskinesia? Biol Psychiatry 14:699-703

Fri CG, Fritz-Axel W, Goran S (1974): Simultaneous quantification of homovanillic acid and 5-hydroxyindoleacetic acid in cerebrospinal fluid by mass fragmentography. Life Sci 14:2469-2480

Gardos G, Cole J (1978): Maintenance antipsychotic therapy: For whom and how long? In Lipton M, Dimascio A, Killam KR (eds), Psychopharmacology: A generation of progress. New York, Raven Press, pp 1179-1184

Glick SM, Roth SJ, Yallow RS, Benson SA (1963): Immunoassay of human GH in plasma. Nature 199:784-787

Herz MI, Glazer WM, Master MA, Sheard MH, Szymanski HV, Hafez H, Mirza M, Vaha J (1991): Intermittent versus maintenance medication in schizophrenia: Two year results. Arch Gen Psychiatry 48:333-339

Herz MI, Melville C (1980): Relapse in schizophrenia. Am J Psychiatry 137:801-805

Hogarty GE, McEvoy JP, Munetz M, DiBarry AL, Bartone P, Cather R, Cooley SJ, Ulrich RF, Carter M, Madonia MJ (1988): Environmental/personal indicators in the course of schizophrenia: Dose of fluphenazine, familial expressed emotion and outcome in schizophrenia. Arch Gen Psychiatry 45:797-805

Hunt JJ, Singh H, Simpson GM (1988): Neuroleptic-induced supersensitivity psychosis: Retrospective studies of schizophrenic inpatients. J Clin Psychiatry 49:258-261

Janowsky DS, Davis JM (1976): Methylphenidate, dextroamphetamine, and levamphetamine. Effects on schizophrenic symptoms. Arch Gen Psychiatry 33:304-308

Janowsky DS, El-Yousef MK, Davis JM, Sekerke J (1973): Provocation of schizophrenic symptoms by intravenous administration of methylphenidate. Arch Gen Psychiatry 28:185-191

Jody D, Lieberman JA, Geisler S, Szymanski S, Alvir JMJ (1990): Behavioral response to methylphenidate and treatment outcome in first episode schizophrenia. Psychopharmacol Bull 26:224-230

Jolley AG, Hirsch SR, McRink A, Manchanda R (1989): Trial of brief intermittent prophylaxis for selected schizophrenic outpatients: Clinical outcome at one year. Br Med J 298:985-990

Kalivas PW, Duffy P, Dilts R, Abhold R (1988): Enkephalin modulation of $A 10$ dopamine neurons: $A$ role in dopamine sensitization. In Kalivas PW, Nemeroff CB (eds), The Mesocorticolimbic Dopamine System, vol 537, The New York Academy of Sciences, pp 405-414

Kane J, Lieberman J (1987): Maintenance pharmacotherapy in schizophrenia. In Meltzer HY (ed), Psychopharmacology Third Generation of Progress: The Energetic of Molecular Biology and Biological Psychiatry, vol 113, New York, Raven Press, pp 1103-1110

Kane J, Woerner M, Lieberman J (1985a): Tardive dyskinesia: Prevalence, incidence, and risk factors. In Chase $T$, Casey D, Gerlach J, Christensen V (eds), Dyskinesia Research and Treatment, Berlin-Heidelberg, SpringerVerlag, pp 72-77

Kane JM, Rifkin A, Woerner M, Reardon G, Sarantakos S, Schiebel D, Ramos-Lorenzi J (1983): Low dose neuroleptic treatment of outpatient schizophrenics. Arch Gen Psychiatry 40:893-896
Kane JM, Rifkin A, Woerner M, Readon G, Kreisman D, Blumenthal R, Borenstein M (1985b): High dose versus low dose strategies in the treatment of schizophrenia. Psychopharmacol Bull 21:533-537

Lee ET (1980): Statistical Methods of Survival Data Analysis. Belmont, CA, Lifetime Learning Publications

Lee TH, Ellinwood EH, Nishita JK (1988): Dopamine receptor sensitivity changes with chronic stimulants. In Kalivas PW, Nemeroff CB (eds), The Mesocorticolimbic Dopamine System, vol 537, The New York Academy of Sciences, pp 324-329

Lieberman J, Jody D, Geisler S, Vital-Herne J, Alvir J, Walsleben J, Woerner M (1989): Treatment Outcome of First Episode Schizophrenia. Psychopharmacol Bull 25:92-96

Lieberman J, Kane J, Woerner M, Weinhold P, Basavaraju N, Kurucz J, Bergmann K (1984): Prevalence of Tardive Dyskinesia in Elderly Samples. Psychopharmacol Bull 20:382-386

Lieberman J, Kane J, Woerner M, Alvir J, Borenstein M, Novacenko H (1986a): Prediction of Relapse in Schizophrenia. Clin Neuropharmacol 13:434-435

Lieberman JA, Kane JM, Sarantakos S, Gadaleta D, Woerner M, Alvir J, Ramos-Lorenzi J (1986b): Prediction of Relapse in Schizophrenia. Psychopharmacol Bull 22(3):845-853

Lieberman JA, Kane JM, eds (1986c): Predictors of Relapse in Schizophrenia. Washington, DC, American Psychiatric Press

Lieberman JA, Kane JM, Alvir J (1987a): Provocative tests with psychostimulant drugs in schizophrenia. Psychopharmacology 91:415-433

LiebermanJA, Kane JM, Sarantakos S, Galadeta D, Woerner M, Alvir J, Ramos-Lorenzi J (1987b): Prediction of Relapse in Schizophrenia. Arch Gen Psychiatry 44:597-603

Lieberman JA, Kane JM, Gadaleta D, Brenner R, Lesser MS, Kinon B (1984): Methylphenidate challenge as a predictor of relapse in schizophrenia. Am J Psychiatry 41: 633-638

Lieberman JA, Alvir JMJ, Woerner M, Degreef G, Bilder R, Ashtari M, Bogerts B, Mayerhoff DI, Loebel A, Levy D, Hinrichsen G, Szymanski S, Chakos M, Borenstein M, Kane JM (1991): Prospective study of psychobiology in furst episode schizophrenia at Hillside Hospital: Design, methodology, and summary of findings. Schizophr Bull 18(3):351-371

Marder SR, van Putten T, Mintz J, Lebell M, McKenzie J, May PRA (1987): Low and conventional dose maintenance therapy with fluphenazine decanoate: Two year outcome. Arch Gen Psychiatry 44:510-517

McMillen BA (1983): CNS stimulants: Two distinct mechanisms of action for amphetamine-like drugs. Trends Pharmacol Sci 429-432

Mueller-Spahn F, Ackenheil M, Albus M, May G, Naber D, Welter D, Zander K (1984): Neuroendocrine effects of apomorphine in chronic schizophrenic patients under long-term neuroleptic therapy and after drug withdrawal: Relations to psychopathology and tardive dyskinesia. Psychopharmacology 84:436-440

Newcomer JW, Riney SJ, Winogradov S, Csernansky JG (1992): Plasma prolactin and homovanillic acid as markers for psychopathology and abnormal movements during maintenance haloperidol treatment in male patients with schizophrenia. Psychiatry Res 41:191-202 
Piazza PV, Deminière JM, Le Moal M, Simon H (1989): Factors that predict individual vulnerability to amphetamine self-administration. Science 245:1511-1513

Pietzcker A, Gaebel W, Kopcke W, Linden M, Muller P, Muller-Spohn F, Schussler G, Tegeler J (1986): A German multi-center study on the neuroleptic long-term therapy of schizophrenic patients' preliminary report. Pharmacopsychiatry 19:161-166

Robinson DR, Bailine S, Lieberman J (1988): Dysphoria associated with methylphenidate infusions. Letter to editor, Am J Psychiatry 145:1321-1322

Roth RH, Tam SY, Ida Y, Yang J, Deutch AY (1988): Stress and the mesocorticolimbic dopamine systems. In Kalivas PW, Nemeroff CB (eds), The Mesocorticolimbic Dopamine System, vol 537, The New York Academy of Sciences, pp 138-147

Schooler NR (1991): Maintenance Medication for Schizophrenia: Strategies for Dose Reduction. Schizophr Bull 17(2):311-324

Schooler NR, Keith SJ, Severe JB, Matthews SM (1993): Treatment strategies in schizophrenia: Effect of dose reduction and family treatment on outcome. Schizophr Res 9:261
Sinha YN, Selby FW, Lewis OJ, Vanderlaan WP (1973): A homologous RIA for human prolactin. J Clin Endocrinol Metab 36:509

Spitzer RL, Endicott J, Robbins E (1977): Research Diagnostic Criteria (RDC) for a Selected Group of Functional Disorders, 3rd ed. New York State Psychiatric Institute

van Kammen D, Bunney W, Docherty J et al. (1982): D-Amphetamine induced heterogenous changes in psychotic behavior in schizophrenia. Am J Psychiatry 139: 991-997

Weinberger DR, Bigelow LB, Klein SY, Wyatt RJ (1981): Drug withdrawal in chronic schizophrenic patients. In search of neuroleptic-induced supersensitivity psychosis. JClin Psychopharmacol 1(3):120-123

Wistedt B, Jorgenson A, Wiles D (1982): A depot neuroleptic withdrawal study: Plasma concentration of fluphenazine and flupenthixol and relapse frequency. Psychopharmacology 78:301-304

Zander K, Fischer B, Zimmer R, Ackenheil M (1981): Longterm neuroleptic treatment of chronic schizophrenic patients: Clinical and biochemical effects of withdrawal. Psychopharmacology 73:43-47 